\title{
LITERATURE REVIEW : HUBUNGAN ANTARA CARING DAN KOMUNIKASI TERAPEUTIK DENGAN KUALITAS PELAYANAN KEPERAWATAN
}

\author{
Irbah Muthmainah Indarti Putri ${ }^{1)}$, Kristina Everentia Ngasu ${ }^{2)}$ \\ ${ }^{1}$ Mahasiswa Program S1 Keperawatan STIKes Yatsi Tangerang 15113, Indonesia \\ ${ }^{2}$ Dosen Keperawatan STIKes Yatsi Tangerang 15113, Indonesia \\ irbahmutmainah@gmail.com
}

\begin{abstract}
Abstrak
Pelayanan keperawatan merupakan bagian integral dari pelayanan kesehatan rumah sakit, yang mempunyai posisi sangat strategis dalam upaya meningkatkan mutu pelayanan konsumen yang datang ke rumah sakit. Tujuan sistematik review ini dibuat adalah untuk mengetahui gambaran mengenai hubungan antara caring dan komunikasi terapeutik dengan kualitas pelayanan keperawatan. Metode yang digunakan dengan pencarian data base artikel terdiri dari studi kuantitatif yang dikumpulkan dari basis data base scholar terbitan tahun 2015-2020. Hasil menunjukkan bahwa caring baik sehingga pasien merasa puas dan komunikasi terapeutik baik sehingga pasien merasa puas terhadap kualitas yang diberikan dalam pelayanan keperawatan. Kesimpulan kualitas pelayanan kesehatan memiliki pengaruh terhadap frekuensi tingkat kepuasan pasien semakin baik kualitas pelayanan kesehatan maka semakin baik pula frekuensi tingkat kepuasan pasien. Maka,ada hubungan yang signifikan antara caring dan komunikasi terapeutik dengan kualitas pelayanan keperawatan.
\end{abstract}

Kata kunci : caring, komunikasi terapeutik, kualitas pelayanan keperawatan

\begin{abstract}
Nursing services are an integral part of hospital health services, which have a very strategic position in an effort to improve the quality of customer service who comes to the hospital. The purpose of this systematic review is to determine the relationship between caring and therapeutic communication with the quality of nursing services. The method used to search for the article database consisted of quantitative studies collected from the scholar database published in 2015-2020. The results show that caring is good so that patients feel satisfied and therapeutic communication is good so that patients feel satisfied with the quality provided in nursing services. The conclusion is that the quality of health services has an influence on the frequency of patient satisfaction, the better the quality of health services, the better the frequency of patient satisfaction levels. Thus, there is a significant relationship between caring and therapeutic communication with the quality of nursing services.
\end{abstract}

Keywords: caring, therapeutic communication, quality of nursing services

\section{Pendahuluan}

Dunia perumahsakitan mendapat tantangan besar untuk meningkatkan kualitas pelayanan berstandar akreditasi Internasional. Peningkatan kualitas pelayanan sangatlah penting agar rumah sakit mampu berkompetensi baik di tingkat regional, nasional bahkan Internasional. Standar internasional untuk sistem manajemen kualitas bertujuan menjamin kesesuaian dari suatu proses pelayanan terhadap kebutuhan persyaratan yang dispesifikasikan oleh pelanggan dan rumah sakit adalah akreditasi internasional dari 
Join Commission International (JCI). Rumah sakit berupaya meningkatkan pelayanan keperawatan yang merupakan ujung tombak dalam melayani pelanggan (Joint Commission International Standar Akreditasi Rumah Sakit, 2011)

Prioritas utama rumah sakit agar dapat bertahan dalam persaingan adalah peningkatan pelayanan terhadap pelanggan. Pelayanan keperawatan merupakan bagian integral dari pelayanan kesehatan rumah sakit, yang mempunyai posisi sangat strategis dalam upaya meningkatkan mutu pelayanan konsumen yang datang ke rumah sakit. Pelayanan keperawatan adalah keseluruhan fungsi, tugas, kegiatan dan tanggung jawab yang dilaksanakan oleh perawat dalam praktek profesi. Kompetisi yang meningkat di era globalisasi menurut pelayanan kesehatan yang memberi kemudahan dalam akses, keramahtamahan, harga bersaing, keterbukaan informasi dan kemasan yang baik (Setyadi, 2013).

Keperawatan adalah salah satu bentuk pelayanan professional yang merupakan bagian integral dari pelayanan kesehatan berdasarkan ilmu dan kiat keperawatan berbentuk pelayanan biologis, psikologis, sosial dan spiritual yang komprehensif/holistik yang ditujukan kepada individu, keluarga dan masyarakat baik dalam keadaan sehat atau sakit yang mencakup seluruh proses kehidupan manusia. Sebagai bagian integral dari pelayanan kesehatan di rumah sakit, pelayanan keperawatan memiliki peran yang amat penting dan memiliki daya ungkit yang besar untuk mencapai pembangunan bidang kesehatan (Dirjen bina upaya kesehatan kementrian kesehatan RI, 2011). Salah satu aspek dari dimensi pelayanan keperawatan yang dapat mempengaruhi kualitas pelayanan keperawatan dan kepuasan pasien adalah pemberian informasi yang jelas, komunikasi yang efektif, dan pendidikan kesehatan yang diperlukan oleh pasien tambahkan juga tentang caring itu penting sehingga mengantar untuk benang merahnya menulis di paragraph selanjutnya ttg caring (Potter \& Perry dalam Roup, 2016).

Caring merupakan bentuk perilaku dalam keperawatan dalam memberi asuhan dengan meningkatkan keselamatan dan keamanan klien untuk membantu sembuh dari penyakitnya . Caring adalah fenomena universal yang mempengaruhi seseorang dalam cara berfikir, cara merasakan dan cara berperilaku dalam berhubungan dengan orang lain (Potter \& Perry dalam Roup, 2016). Hal ini merupakan inti dari praktik keperawatan dimana perawat membantu klien sembuh dari penyakitnya, memberikan penjelasan tentang penyakitnya, serta membina hubungan saling percaya dengan klien (Potter \& Perry dalam Roup, 2016).

Berdasarkan fenomena yang telah terjadi dalam dunia keperawatan, caring dapat diterima sebagai nilai disiplin, menghormati orang lain, memberikan perhatian, kepedulian, dan bersikap empati. Dengan menerapkan nilai ini perawat dapat membina hubungan saling percaya yang harmonis antara perawat dengan pasien, dapat memenuhi kebutuhan dasar pasien, sehingga dapat memberikan kepuasan pasien kepada perawat. Karena itu, perawat harus bersikap caring agar tidak terjadi hal yang memburuk atau terjadi kesalahpahaman dalam perawatan antara pasien dengan perawat (Suweko \& Warsito, 2019). 
Perilaku caring dapat memberikan keuntungan bagi pelayanan kesehatan (rumah sakit) termasuk pada kepuasan pasien. Menurut Ardiana dalam Roup (2016), menyatakan bahwa perilaku caring dapat memberikan manfaat secara finansial/keuangan bagi industri pelayanan kesehatan (rumah sakit). Ardiana dalam Roup (2016) juga menambahkan bahwa perilaku caring staf tenaga kesehatan (termasuk perawat) memiliki nilai ekomomi bagi rumah sakit karena memiliki dampak terhadap kepuasan pasien.

Nkambule Bongi. S, (2019) dalam penelitiannya tentang The relationship between patient's perception of nurse caring behaviors and tuberculosis stigma among patients with drug-resistant tuberculosis in Swaziland menyatakan bahwa dari 84 responden persepsi pasien tentang perilaku caring perawat baik 52,8\% dengan skala (ketulusan, rasa empati, dan rasa hormat). Ada korelasi antara persepsi perilaku caring perawat dan stigma TB $(r=0,709, p<0,01)$. Perilaku merawat perawat dapat memprediksi stigma terkait TB $(\mathrm{p}<0,01)$ dengan dijelaskan varians $52,8 \%$ dan dengan sub skala "Ketulusan, Empati \& Rasa Hormat" menjadi prediktor terkuat $(\beta=0.599)$.

Hasil penelitian Pratiwi \& Pertiwi (2018) tentang Hubungan Komunikasi Terapeutik dan Caring Dengan Kepuasan Pasien Terhadap Perawat Ruang Rawat Inap Penyakit Dalam Rumah Sakit Umum Multazam Medika Bekasi Timur menyatakan bahwa nilai frekuensi caring perawat dari 40 responden dengan caring perawat rendah sebanyak 23 responden dengan persentase sebesar (57,5\%), dan dengan caring perawat tinggi sebanyak 17 responden dengan persentase sebesar $(42,5 \%)$. Hasil bivariat dari uji statistic chi-squere diperoleh ada hubungan hubungan caring dengan kepuasan pasien dengan $\mathrm{Ha} 2$ diterima dan Ho2 ditolak dengan nilai $\mathrm{p}=0,001<\alpha=0,05$ artinya ada hubungan yang signifikan antara caring dengan kepuasan pasien.

Perawat merupakan seorang yang memberikan jasanya kepada pasien, keluarga pasien, dan masyarakat baik sakit maupun sehat yang mencakup seluruh proses kehidupan manusia. Perawat sebagai petugas yang selalu berhubungan dengan pasien harus memiliki banyak keterampilan, salah satunya adalah keterampilan interpersonal yaitu keterampilan dalam komunikasi dengan pasien. komunikasi merupakan proses kompleks yang melibatkan perilaku dan memungkinkan individu untuk berhubungan dengan orang lain dan dunia sekitarnya. Perawat yang memiliki keterampilan berkomunikasi secara terapeutik tidak mudah menjalin hubungan rasa percaya dengan klien, mencegah terjadinya masalah ilegal, memberikan kepuasan profesional dalam pelayana keperawatan menigkatkan citra profesi keperawatan dan Rumah Sakit (Nugroho \& Aryati, 2013).

Menurut Saprilla A (2018) tentang pengaruh responsiveness perawat dalam praktik komunikasi terapeutik terhadap kepuasan pasien di instalasi rawat inap RSU Haji Surabaya menjelaskan bahwa dengan komunikasi terapeutik pasien akan merasa terbantu dalam memperjelas dan memahami kondisi kesehatannya sehingga akan berkurang perasaan ragu, cemas, dan takut terkait kondisi dan segala tindakan penyembuhan yang akan atau sedang diterima. Selain itu dapat pula mengidentifikasi, 
mengungkapkan perasaan, dan mengkaji masalah serta mengevaluasi tindakan yang dilakukan oleh perawat, membantu pasien dalam mengambil keputusan tindakan, serta mempengaruhi pasien dalam mengambil keputusan tindakan.

Berdasarkan hasil penelitian yang dilakukan Fite Robera Olana, (2019). tentang Predictors of therapeutic communication between nurses and hospitalized patients menyatakan bahwa 33,9\% perawat memiliki komunikasi terapeutik yang rendah. Mengenai waktu yang tersedia untuk perawatan, $36 \%$ dari pasien yang dirawat setuju bahwa itu mempengaruhi komunikasi terapeutik. Prediktor signifikan implementasi

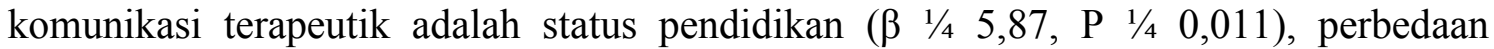
bahasa $\left(\beta 1 / 4-6, \mathrm{P}^{1 / 4} 0,014\right)$, perbedaan pendidikan $\left(\beta^{1 / 4} 5,21, \mathrm{P}^{1 / 4} 0,010\right)$ dan pandangan pasien yang dirasakan skor $(\beta 1 / 43,57, \mathrm{P} \quad 0,001)$.

Menurut Transyah \& Toni (2018) tentang Hubungan Penerapan Komunikasi Terapeutik Perawat Dengan Kepuasan Pasien di Ruang Rawat Inap Interne RSUD dr. Rasidin Padang Tahun 2017 menyatakan bahwa dari 70 orang responden terdapat lebih dari separuh $40(57,1 \%)$ perawat tidak baik dalam melakukan penerapan komunikasi terapeutik. Terdapat hubungan yang bermakna antara kepuasan pasien dengan pelaksanan komunikasi terapeutik perawat di ruang rawat inap interne RSUD dr. Rasidi Padang tahun $2017(\mathrm{p}=0,003(<0,05)$

Penelitian yang diteliti oleh Shin Nayeon and Park Jummi (2018) The Effect of Intentional Nursing Rounds Based on the Care Model on Patients' Perceived Nursing Quality and their Satisfaction with Nursing Services menyatakan bahwa tingkat kualitas pelayanan keperawatan yang dipersepsikan oleh kelompok eksperimental dengan 70 responden $(4,48)$ lebih tinggi daripada kelompok control dengan 75 responden $(3,80)$.

Menurut hasil penelitian Rusnoto. dkk (2019) tentang Hubungan Pelayanan Keperawatan dan Komunikasi Terapeutik dengan Kepuasan PasienRawat Inap di RSUD Dr. Loekmono Hadi Kudus menyatakan bahwa sebagian besar responden menyatakan pelayanan keperawatan masuk pada kategori baik (71\%) dan sebagian kecil menyatakan pelayanan keperawatan masuk pada kategori kurang baik (29\%). Dari data pendahuluan yang peneliti lakukan diperoleh data bahwa masih ada perawat yang tidak menerapkan perilaku caring dan komunikasi terapeutik dalam memberikan pelayanan keperawatan sehingga pasien merasa tidak puas. Hal ini dikarenakan perawat kurang maksimal dalam memberikan pelayanannya seperti kurang empati, perhatian, dan melakukan komunikasi interpersonal.

Berdasarkan uraian diatas maka penulis tertarik untuk meneliti hal ini dan dituangkan dalam bentuk penulisan tugas akhir yang berjudul "Study Literature Review : Hubungan Antara Caring dan Komunikasi Terapeutik Dengan Kualitas Pelayanan Keperawatan “. 


\section{Metode}

Metode pengumpulan data yang digunakan dalam penelitian ini dimulai dengan menentukan topic, kata kunci dan kriteria inklusi dan ekslusi. Alur untuk mendapatkan artikel yang memenuhi kristeria inklusi dan ekslusi mengikuti alur Preferred Reporting Items for Systematic Reviews and Meta-analyses (PRISMA). Salah satu tahap dalam prisma adalah melakukan Ekstraksi Jurnal. Data yang digunakan dalam penelitian ini berasal dari hasil-hasil penelitian yang sudah dilakukan dan diterbitkan dalam jurnal online nasional dan internasional. Dalam melakukan pencarian jurnal penelitian yang dipublikasikan di internet menggunakan Google Schoolar dan Elsevier dengan kata kunci yang disesuaikan dengan mengikuti tahapan atau protokol penelitian yang benar dengan format PRISMA (Moher et al., 2009)

\section{Gambar 1. Tahapan Prisma}

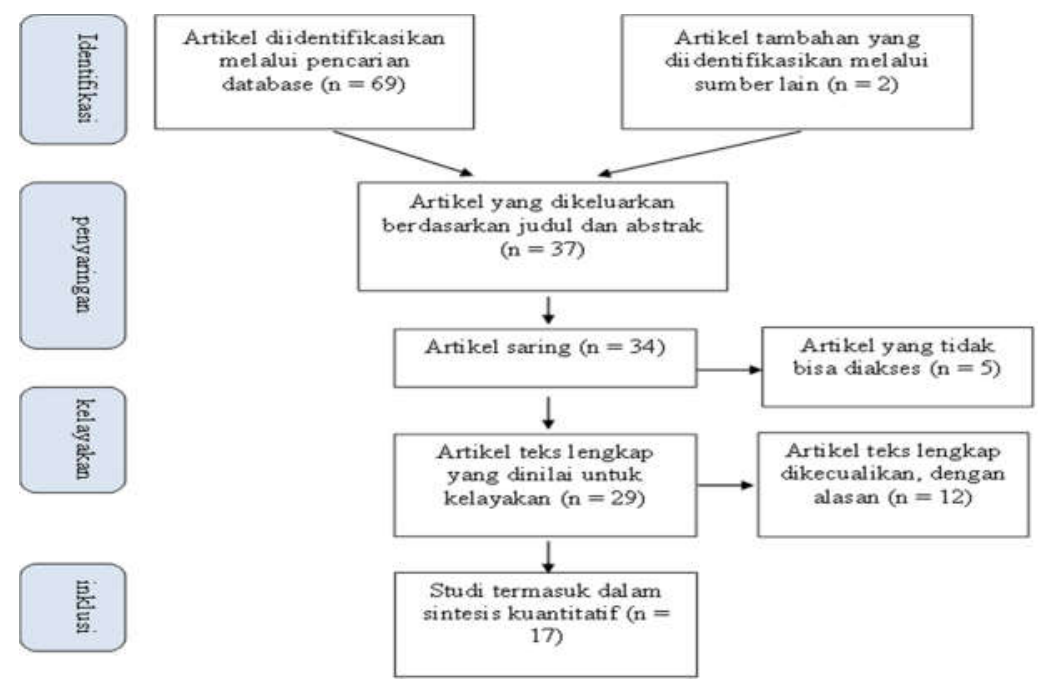

(Sumber: Moher et al.,2009)

\section{Hasil dan Pembahasan}

Berdasarkan Tabel 4.5 Hasil Tabulasi Literature Review pada 9 jurnal diatas, setiap jurnal menunjukkan bahwa caring dan komunikasi sangat berhubungan dengan kualitas pelayanan keperawatan.

\section{Caring Dengan Kualitas Pelayanan Keperawatan}

Menurut Potter dan Perry (2009) menyebutkan caring sebagai suatu cara pemeliharaan berhubungan dengan menghargai orang lain, disertai perasaan memiliki dan bertanggung jawab. Caring adalah fenomena universal yang mempengaruhi cara manusia berfikir, merasa, dan mempunyai hubungan dengan sesama. 
Caring merupakan suatu bentuk perhatian perawat dengan sepenuh hati terhadap pasien, kepedulian, empati, komunikasi yang lemah lembut dan rasa kasih sayang perawat terhadap pasien akan membentuk hubungan perawat-klien yang teraupetik (AbuRuz et al, 2015 dalam Yunita, 2019).

Kepuasan pasien merupakan faktor yang sangat penting untuk mengevaluasi mutu pelayanan keperawatan yang dilakukan oleh perawat di rumah sakit dan perilaku caring perawat adalah salah satu aspek yang berhubungan dengan pelayanan keperawatan, karena caring mencakup hubungan antar manusia dan berpengaruh terhadap mutu pelayanan dan kepuasan pasien. Kepuasan pasien dapat dinilai dari beberpa dimensi yang meliputi: tangibles, reliability, responsiveness, assurance dan emphaty (Nursalam, 2015 dalam Yunita, 2019).

Hal ini didukung oleh teori (Pohan 2007) yang menyatakan bahwa kualitas pelayanan kesehatan memiliki pengaruh terhadap frekuensi tingkat kepuasan pasien semakin baik kualitas pelayanan kesehatan maka semakin baik pula frekuensi tingkat kepuasan pasien.

Tabulasi dari hasil literature review yang menggambarkan hasil univariat caring dari setiap artikel bahwa terdapat jurnal yang presentase caring tinggi sebanyak 3 jurnal yaitu $69.3 \%-100 \%$, sementara presentasi caring yang rendah ada pada 2 jurnal berkisar antara 51.1\% - 57.5\% yaitu penelitian menurut penelitian (pratiwi.R dan Pertiwi.D) dan (Donny Sahensolar dan Ervina Avianti).

Tabulasi dari hasil literature review yang menggambarkan hasil bivariat caring dari setiap jurnal.bahwa caring dengan kepuasan pasien memiliki hubungan yang signifikan dengan nilai $p$ value berkisar antara 0,001 Sampai $0,002(p<0,05)$, artinya ada hubungan antara caring dan kepuasan pasien.

Perilaku caring perawat sangat mempengaruhi kepuasan pasien, apabila pelayanan yang diberikan sudah sesuai dengan kebutuhan pasien dan diberikan dengan cara yang ramah pada waktu mereka dirawat sesuai sumber daya yang dimiliki, maka pasien akan merasakan kepuasan yang tinggi. Dapat disimpulkan bahwa ada hubungan caring dengan kualitas pelayanan keperawatan.

\section{Komunikasi Terapeutik Dengan Kualitas Pelayanan Keperawatan}

Komunikasi terapeutik perawat merupakan komunikasi yang dilakukan perawat dan pasien dalam menjalin komunikasi profesional perawat (Purwanto, 2014 dalam Barakati Conny A, 2016). Komunikasi terapeutik diterapkan oleh perawat dalam berhubungan dengan pasien untuk meningkatkan rasa saling percaya, dan apabila tidak diterapkan akan menganggu hubungan terapeutik yang berdampak pada ketidakpuasan pasien. Pasien akan merasa puas ketika kinerja layanan kesehatan yang diperolehnya sama atau melebihi harapannya dan sebaliknya, ketidakpuasaan atau perasaan kecewa pasien akan 
muncul apabila kinerja layanan kesehatan yang diperolehnya itu tidak sesuai dengan harapannya (Djoko, 2014 dalam Barakati Conny A, 2016).

Faktor yang mempengaruhi kepuasan pasien adalah komunikasi terapeutik. Komunikasi terapeutik merupakan hal yang sangat penting bagi perawat untuk mendukung proses keperawatan yang meliputi pengkajian diagnosa keperawatan, perencanaan, pelaksanaan dan penilaian(Wijono, 2010 Lontoh Esther, 2017). Dimensi mutu pelayanan rumah sakit yaitu yang mempengaruhi mutu pelayanan salah satunya merupakan dimensi hubungan perawat dengan pasien (Sulistiyaningsih, 2007 dalam Lontoh Esther, 2017).

Tabulasi dari hasil literature review yang menggambarkan hasil univariat komunikasi terapeutik dari setiap artikel bahwa terdapat jurnal yang presentasi komunikasi terapeutik baik berkisar antara $19,1 \%$ Sampai $79,4 \%$ dan yang tinggi hanya 1 jurnal yaitu $79,4 \%$ sedangkan yang komunikasi tidak baik berkisar antara 19,1\% Sampai $66,7 \%$ dan yang rendah diatas $50 \%$ ada 4 jurnal berkisar antara $52,5 \%$ sampai $66,7 \%$.

Tabulasi dari hasil literature review yang menggambarkan hasil bivariat komunikasi terapeutik dari setiap artikel bahwa terdapat 8 jurnal yang memiliki hubungan yang signifikan dengan nilai $p$ value berkisar antara 0,000 Sampai $0,003(\mathrm{p}<0,05)$ sedangkan 1 jurnal tidak memiliki hubungan yang signifikan antara komunikasi terapeutik dengan kepuasan pasien yaitu penelitian menurut mahendro dan kusumo dengan hasil $p$ value $>0,006(\mathrm{p}=<0,05)$.

Komunikasi terapeutik sangat mempengaruhi kepuasan pasien apabila pelayanan yang diberikan sudah sesuai dengan kebutuhan pasien dan diberikan dengan cara yang ramah pada waktu mereka dirawat sesuai sumber daya yang dimiliki, maka pasien akan merasakan kepuasan yang tinggi. Dapat disimpulkan bahwa adanya hubungan komunikasi terapeutik dengan kualitas pelayanan keperawatan.

\section{Kesimpulan}

Hasil dari kajian literature ini menunjukkan bahwa :

1. Caring terhadap kepuasan pasien memiliki hubungan yang signifikan dengan nilai $p$ value berkisar antara 0,001 Sampai $0,002(\mathrm{p}<0,05)$, artinya ada hubungan antara caring dan kepuasan pasien.

2. Komunikasi terapeutik terhadap kepuasan pasien memiliki hubungan yang signifikan terdapat 8 jurnal dengan nilai $p$ value berkisar antara 0,000 Sampai $0,003(\mathrm{p}<0,05)$ sedangkan 1 jurnal tidak memiliki hubungan yang signifikan antara komunikasi terapeutik dengan kepuasan pasien dengan hasil $p$ value $>0,006(\mathrm{p}=<0,05)$.

Kualitas pelayanan kesehatan memiliki pengaruh terhadap frekuensi tingkat kepuasan pasien semakin baik kualitas pelayanan kesehatan maka semakin baik pula frekuensi 
tingkat kepuasan pasien. Dapat disimpulkan bahwa caring dan komunikasi terapeutik memiliki hubungan dengan kualitas pelayanan keperawatan.

\section{Daftar Pustaka}

Dirjen Bina Upaya Kesehatan Kementrian Kesehatan Ri. (2011). Http://Buk.Depkes.Go.Id/

Lontoh, E., \& Dawanaka, J. E. (2017). Hubungan Komunikasi Terapeutik Perawat Dengan Kepuasan Pasien Di Ruang Rawat Inap Interna Rsup Ratatotok Buyat. Journal Of Community \& Emergency, Volume 5 Nomor 1, 1-13.

Nugroho, H. A., \& Aryati, S. (2009). Hubungan antara komunikasi terapeutik perawat dengan kepuasan pasien di Rumah Sakit lslam Kendal. Jurnal Keperawatan, 2(2), 36-41.

Pratiwi, R. D., \& Pertiwi, D. S. (2018). Hubungan Komunikasi Terapeutik Dan Caring Dengan Kepuasan Pasien Terhadap Perawat Ruang Rawat Inap Penyakit Dalam Rumah Sakit Umum Multazam Medika Bekasi Timur. Edudharma Journal, Vol 2 No. 2, 1-22.

Roup, A. (2016). Gambaran Perilaku Caring Perawat Di Ruang Rawat Inap Lantai 4 Gedung A Rsupn Dr. Cipto Mangunkusumo Jakarta. Fik Ui.

Transyah, C. H., \& Toni, J. (2018). Hubungan Penerapan Komunikasi Terapeutik Perawat Dengan Kepuasan Pasien. Jurnal Endurance , 3 (1), 1-8.

Yunita, S., \& Hariadi, P. (2019). Hubungan Perilaku Caring Perawat Dengan Tingkat Kepuasan Pasien Di Rumah Sakit Permata Bunda Medan Tahun 2019. Indonesian Trust Health Journal, Volume 2, No.1, 1-8. 